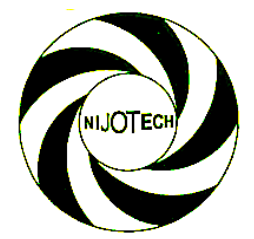

Nigerian Journal of Technology (NIJOTECH)

Vol. 39, No. 4, October 2020, pp. 1021 - 1028

Copyright@ Faculty of Engineering, University of Nigeria, Nsukka,

Print ISSN: 0331-8443, Electronic ISSN: 2467-8821

www.nijotech.com

http://dx.doi.org/10.4314/nit.v39i4.7

\title{
USE OF EXPANDED POLYSTYRENE FROM DISPOSABLE FOOD PACK AS A MODIFIER FOR BITUMEN IN HOT MIX ASPHALT
}

\author{
A. A. Murana ${ }^{1, *}$, K. Akilu ${ }^{2}$ and A. T. Olowosulu ${ }^{3}$ \\ 1,3, Department of Civil Engineering, Ahmadu Bello University, Zaria, Kaduna State, NIGERIA \\ 2, Department of Civil Engineering, Kaduna PolyteChnic, Kaduna, Kaduna State. NIGERIA \\ E-mail addresses; ${ }^{1}$ fatinoyi2007@gmail.com, ${ }^{2}$ kamiluakilu@yahoo.com \\ 3 atolowosulu@gmail.com
}

\begin{abstract}
This study evaluate the use of Disposable Food Pack (DFP) as a modifier for bitumen for an improved Hot Mix Asphalt (HMA). The bitumen was modified with 2\%, 4\%, 6\%, $8 \%$ and $10 \%$ DFP obtained from domestic waste. The penetration, ductility and specific gravity of DFP modified bitumen decreased from $68 \mathrm{~mm}$ to $59.5 \mathrm{~mm}, 110 \mathrm{~cm}$ to $101 \mathrm{~cm}$ and 1.025 to 1.012 respectively with increase in DFP, while softening point increased from $49.5^{\circ} \mathrm{C}$ to $54.5^{\circ} \mathrm{C}$ with increase in DFP. The Marshal Stability results revealed that the DFP modified bitumen increased the stability values of the compacted mixes to a maximum of $9.33 \mathrm{kN}$ at $8 \%$ DFP content. The flow showed decrease from $3.18 \mathrm{~mm}$ at $2 \%$ DFP to $2.94 \mathrm{~mm}$ at $10 \%$ DFP, whereas the density of the compacted mixes increased to a maximum of $2.293 \mathrm{~g} / \mathrm{cm}^{3}$ with increased modifier. An Optimum DFP Content of $6.7 \%$ by weight of the Optimum Bitumen Content (OBC) is recommended.
\end{abstract}

Keywords: Bitumen, Disposable Food Pack, Expanded Polystyrene, Hot Mix Asphalt, Modified bitumen

\section{INTRODUCTION}

The plastic wastes emanating from poorly disposed Food Pack, a product of Expanded Polystyrene (EPS), used in packaging food in Nigeria, are found as litters on streets, roads and highways in major cities of Nigeria due to the inability of EPS to biodegrade. This unfortunate situation is compounded by several factors including the poor attitude of the average Nigerian towards waste disposal. It is common place to find beaches, rivers, gutters and roadsides which are choked and filled with DFP as shown in Figure 1. The need for efficient solid waste management and alternative recycling regimes to curb this trend cannot be over-emphasized.

Nigeria as a developing country is experiencing genuine difficulty in the area of proper solid waste disposal and management. Worldwide, plastic products contribute substantially to an ever increasing volume of municipal solid waste (MSW) streams.

\footnotetext{
* Corresponding author, tel: +234-803-637-6697
}

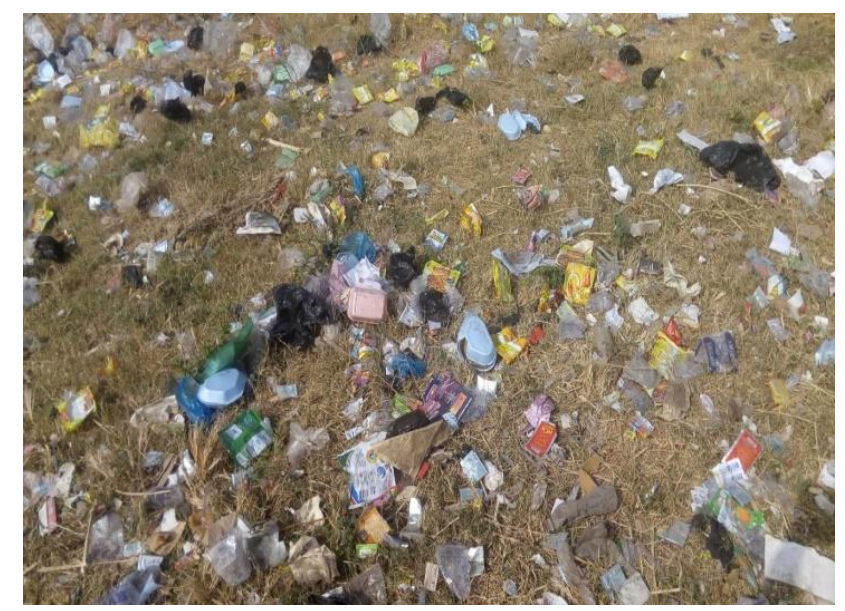

Figure 1: Waste Food Packs From Domestic Waste

Globally, it constitutes $7-9 \%$ of MSW and $2 \%$ in Lagos State, Nigeria [1]. As a result of rapid industrial growth in various fields together with population growth, an obvious increase in waste generation rates for various types of waste materials is observed. Many of the wastes produced today are non-biodegradable that 
will remain in the environment for hundreds of years leading to waste disposal crisis as well as various environmental concerns [2]. According to recent studies, plastics can stay unchanged for as long as 450 years on earth, considering the increase in population and the rising demand of food and other essentials [3].

\section{LITERATURE REVIEW}

Bituminous binders are widely used in road paving and their viscoelastic properties are dependent on their chemical composition. The increased economic activity and higher traffic volumes are rapidly contributing to the deterioration of roads [3]. The need for an enhanced binder which can better withstand adverse road conditions and provide a means to an alternative waste recycling strategy through bitumen modification, led many researchers to explore the feasibility of blending conventional bitumen with waste polymer materials, as successfully reported by [4].

In order to improve the performance of asphalt pavements, many polymeric substances have been incorporated in asphalt mix as additives in many forms. Plastics are durable and degrade very slowly [5].

Polymer modification of bitumen and asphalt mix offers several benefits such as enhanced fatigue resistance, improved thermal cracking resistance, decrease in temperature susceptibility, and improve rutting resistance [6]. Polymer modified binders have been used to overcome tough road conditions and maintain superior performance as compared to conventional binders [7]. The purpose the polymer serves is that of changing the physical properties such as the softening point and brittleness of the bitumen. Ductility can also be improved and this in turn will affect the properties of the aggregate/bitumen mixture in which the modified bitumen is used $[8,9]$. Modified bitumen containing $10 \%$ waste polyethylene can be used in road construction particularly in the warmer region [10]. Low density polyethylene carry bags collected from domestic solid waste can be used as the modification of $80 / 100$ paving grade bitumen $[5,2]$.

It was observed that the addition of processed plastic, about $8.0 \%$ by weight of bitumen, helps in substantially improving the stability or strength, fatigue life and other desirable properties of asphalt concrete mix, even under adverse water-logging conditions [2]. Decrease in consistency and increase in the resistance to flow and temperature changes also appear in PET modified binder [6].
Utilization of wastes from polyethylene terephthalate to modify conventional Bituminous Asphaltic Concrete (BAC) will help remove post-consumer plastic wastes from the waste stream and likewise help enhance the properties of ordinary BAC [11].

In terms of bulk density, pulverized Low-Density Polyethylene plastic waste obtained from "pure water" sachet wastes could be reasonably classified as ultralightweight fine aggregate [1].

\section{AIM AND OBJECTIVES OF THE STUDY}

The aim of this research work is to determine the effect of Disposable Food Pack as a Modifier for Bitumen in Hot Mix Asphalt. The specific objectives are as follows:

1. Carry out a comparative analysis between the pure bitumen and modified bitumen.

2. Determine the general properties of pure bitumen and bitumen modified with $2 \%, 4 \% 6 \%, 8 \%$ and $10 \%$ Disposable Food Pack content.

3. Determine optimum bitumen content and optimum disposable food pack content in the hotmix asphalt.

\section{MATERIALS AND METHODS}

\subsection{Materials}

The materials used for this study are bitumen, modifier and aggregates. The bitumen was $60 / 70$ penetration grade bitumen which was free of any foreign matter like wood and other solid matter. The aggregates were obtained from Eksiogullari Construction Company Ltd Kaduna, Nigeria. The modifier consists of DFP, and was sourced from domestic waste within Kaduna metropolis which is predominantly product of EPS. The DFP was washed thoroughly in a detergent, rinsed with tap water, and sundried in the open to remove any odor. The material was dissolved in kerosene to change its state from solid to viscous as shown in Figure 2.

\subsection{Methods}

Schematic Representation of Experimental design is as presented in Figure 3. Tests were carried out in accordance to the standard specification. For the pure and the modified bitumen, Penetration test [12], Softening point [13], Ductility test [14], Viscosity test [15] and Specific gravity test [16] were carried out. Flash and fire point [17] and the Solubility test [18] were conducted only on the pure bitumen.

The following laboratory tests were conducted to determine the properties of aggregates: Sieve Analysis 
[19]; Aggregate Crushing Value [20]; Aggregate Impact Value [20], Los Angeles Abrasion [20]; Flakiness and Elongation index [21]; and Specific Gravity [22].

Marshall Method for designing hot mix asphalt in accordance to standard specification [23] was used to determine the properties of strength and durability of modified Hot Mix Asphalt.

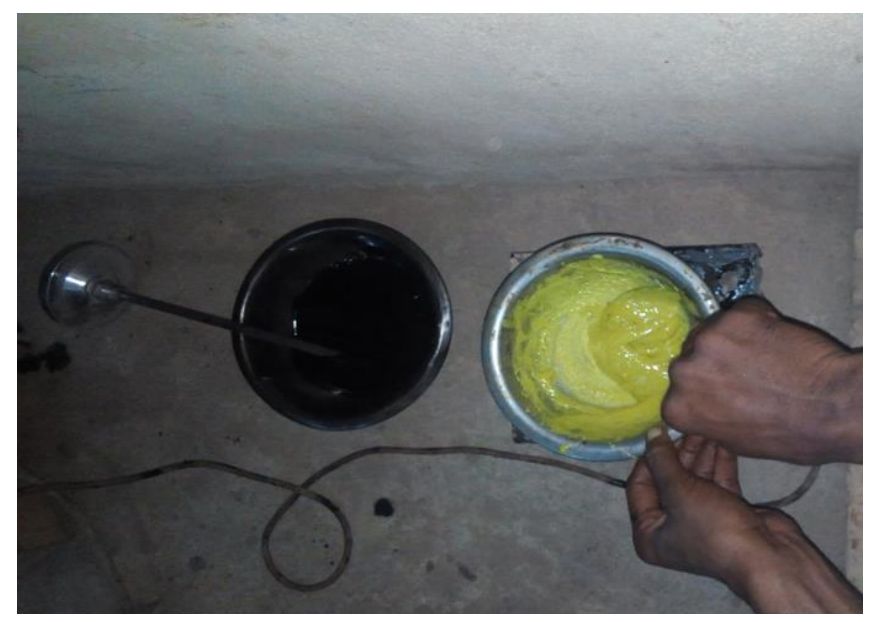

Figure 2: Pure Bitumen and DFP Dissolved in kerosene

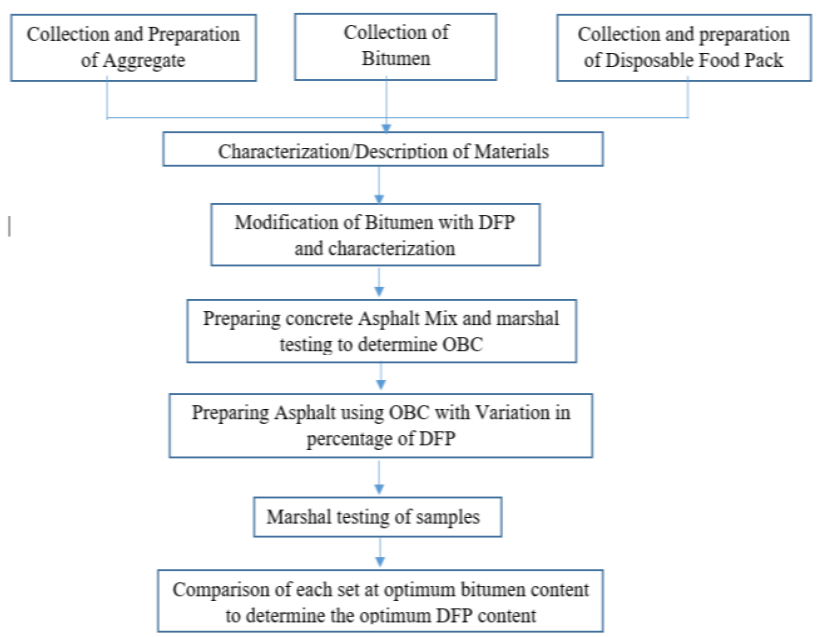

Figure 3: Schematic Representation of Experimental design

\section{RESULTS AND DISCUSSION}

\subsection{Consistency and other general tests on} bitumen

Table 1 shows test results conducted on pure bitumen and are found to be in line with the Nigerian General Specification for Road and Bridges [24], for 60/70 penetration grade bitumen.

\subsubsection{Effect of Modifier on Bitumen Penetration} The penetration tests result is as presented in Figure 4. From Figure 4, the addition of the modifier can be observed to slightly decrease the penetration value of the pure bitumen from $68 \mathrm{~mm}$ to $66.5 \mathrm{~mm}$ with $2 \%$ modifier content. Still, as the modification ratio approaches $10 \%$, the degree of penetration decreased drastically as its value becomes $59.5 \mathrm{~mm}$. This illustrates that the material will show further decrease in penetration value as modifier content is increased; an observation confirmed by the work of [25] who studied the mixing process of polypropylene (PP) modified bituminous concrete.

Table 1: Tests results conducted on pure bitumen

\begin{tabular}{llll}
\hline Test Conducted & Unit & Result & Specification \\
\hline Penetration & $0.1 \mathrm{~mm}$ & 68 & $60-70$ \\
Softening point & ${ }^{\circ} \mathrm{C}$ & 49.8 & $48-56$ \\
Ductility @ 25 ${ }^{\circ} \mathrm{C}$ & $\mathrm{Cm}$ & 110 & 100 (Minimum) \\
Specific gravity & $\mathrm{NIL}$ & 1.025 & $1.01-1.06$ \\
Flash-point & ${ }^{\circ} \mathrm{C}$ & 258 & 250 (Minimum) \\
Fire-point & ${ }^{\circ} \mathrm{C}$ & 220 & $\mathrm{NIL}$ \\
Solubility in $\mathrm{C}_{2} \mathrm{~S}$ & $\%$ & 100 & 99 min \\
\hline
\end{tabular}

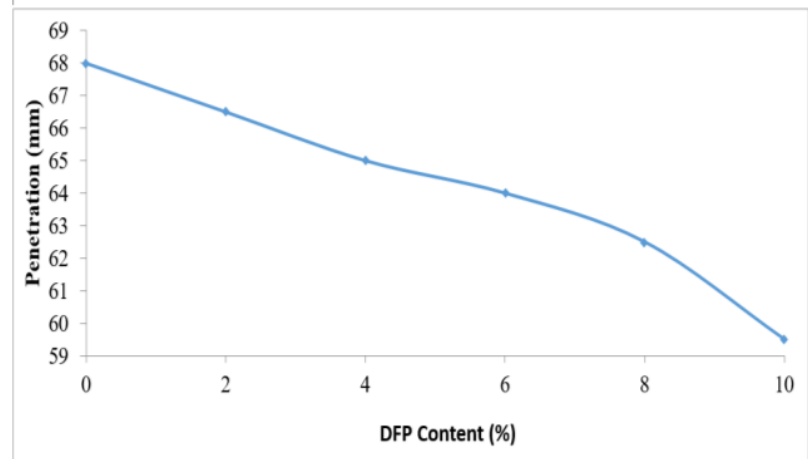

Figure 4: Variation of Penetration with DFP Content

\subsubsection{Effect of modifier on bitumen softening point}

The softening point test result is as presented in Figure 5. From Figure 5, it can be seen that softening point increased to $54.5^{\circ} \mathrm{C}$ from $49.5^{\circ} \mathrm{C}$ at $10 \%$ modifier content. It indicates that temperature susceptibility of binder significantly decreased with modifier content. This shows a similar pattern by [9] where he found that softening point increased to $70^{\circ} \mathrm{C}$ from $50^{\circ} \mathrm{C}$ in case of 10 percent waste plastic content. This indicate that higher temperature will be required to make the modified binder soft as polymer increased consistency of the binder. 


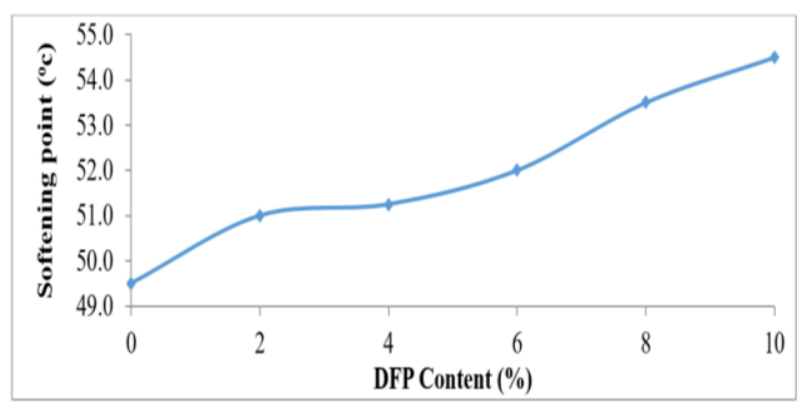

Figure 5: Variation of softening point with DFP Content

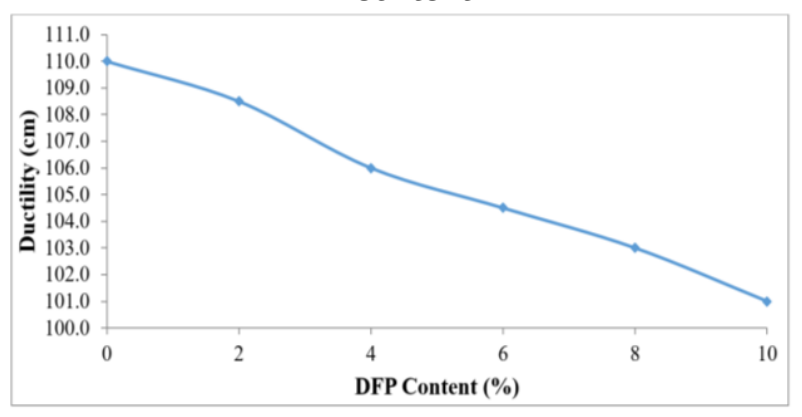

Figure 6: Variation of Ductility with DFP Content

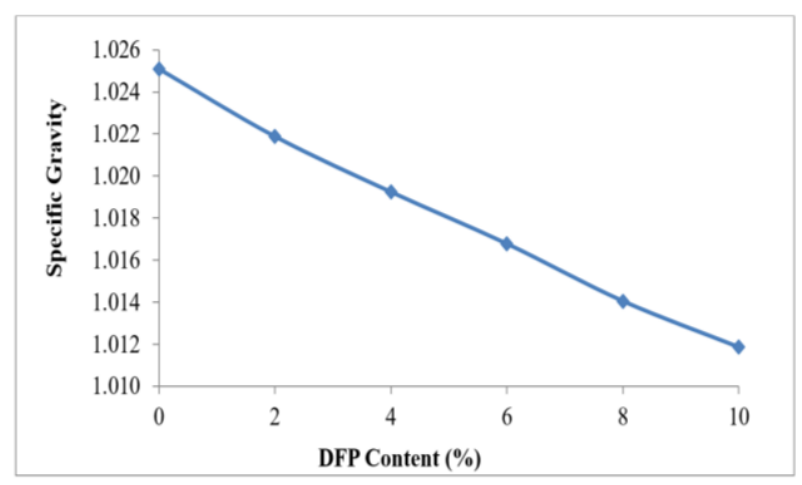

Figure 7: Variation of Specific gravity with DFP

\subsubsection{Effect of modifier on bitumen ductility test}

Ductility test result is as presented in Figure 6 . The result indicates that ductility decreased with increase in modifier content in the binder. The ductility value decreases from $110 \mathrm{~cm}$ to $101 \mathrm{~cm}$ with $10 \%$ Modifier content. As reported by [9], the ductility value decreased from $100 \mathrm{~cm}$ to $20 \mathrm{~cm}$ with $10 \%$ waste plastic.

\subsubsection{Effect of modifier on bitumen specific gravity}

The results of specific gravity test are shown in Figure 7. It was observed that specific gravity of bitumen decreased with the increase of modifier content in bitumen. For $10 \%$ modifier content, this value has decreased from 1.025 to 1.012 . This happened as a result of the specific gravity of the DFP being less than that of the bitumen. A similar trend was observed by
[9] which showed a decreased in specific gravity of the binder from 1.025 to 1.010 with $10 \%$ waste plastics.

\subsection{Aggregates \\ 5.2.1 Sieve analysis}

The proposed aggregates gradation curve was found to be satisfying [24]; as illustrated in the Figure 8 for asphalt wearing course. The proportioning was done using the trial-and-error method. The proportions that finally gave the required gradations were 56,38 , and $6 \%$ for coarse, fine aggregates and mineral filler respectively.

\subsubsection{Tests conducted on aggregates}

The results of the tests conducted on the aggregates are as presented in Table 2. From Table 2, it can be seen that all the quality control tests met up with the [24].

\subsection{Effect of DFP on Properties of Hot Mix Asphalt}

Samples were prepared at $\mathrm{OBC}$ to evaluate the effect of DFP on Hot Mix Asphalt by considering five proportions of DFP $(2,4,6,8$ and $10 \%$ by the weight of $\mathrm{OBC}$ ). The samples were tested for bulk density, stability and flow.

\subsubsection{Stability - DFP content Variation}

Variation of stability with DFP test result is as presented in Figure 9. From Figure 9, the stability increased from $9.13 \mathrm{kN}$ at $2 \%$ DFP to $9.33 \mathrm{kN}$ at $8 \%$ DFP before decreasing at $10 \%$ DFP. This finding indicates that high strength bituminous mixes could be produced by using DFP up to optimum level of $8 \%$ without changing other ingredients. The increase in the stability values of the conventional mixture is due to the improvement of the modified binders to adhesion and cohesion of the asphalt mixture which is attributed to hardening and decreased in the penetration of the pure bitumen in the mix. The study agrees with the work of [8], who study the effect of additives in hot asphalt mixtures and found that the stability $18.5 \mathrm{kN}$ at $6 \%$ modifier content.

\subsubsection{Flow - DFP content variation}

Result on the variation of flow with DFP content for all the DFP percentages is presented in Figure 10. The flow of the modified asphalt mixes were lower than that of the control which decreased from $3.18 \mathrm{~mm}$ at $2 \%$ DFP content to $2.94 \mathrm{~mm}$ at $10 \%$ DFP content. This 
agrees with the result of [5] who noted that reduction in flow suggests that polymer content has increased effect on the internal friction of the mix.

\subsubsection{Bulk density - DFP content variation}

The results of the variation of bulk density with DFP are presented in Figure 11. It can be observed that the bulk density of compacted mixes increases up to $6 \%$ DFP content before decreasing with the increased of DFP at $8 \%$ and $10 \%$ in bitumen. The study shows similar pattern with $[5,8]$, who studied the effect of additives in hot asphalt mixtures and found the bulk density of $2.38 \mathrm{~g} / \mathrm{cm}^{3}$ at $6 \%$ modifier content.

\subsubsection{VMA - DFP content relationship}

The results of VMA analysis are shown in Figure 12. It can be seen that the VMA value decreased to a minimum $18.6 \%$ at $6 \%$ DFP and then increased with the increase in DFP content. This showed a similar trend to that of [25] as VMA decreased to $17.5 \%$ at $2.5 \%$ before showing an increased pattern.

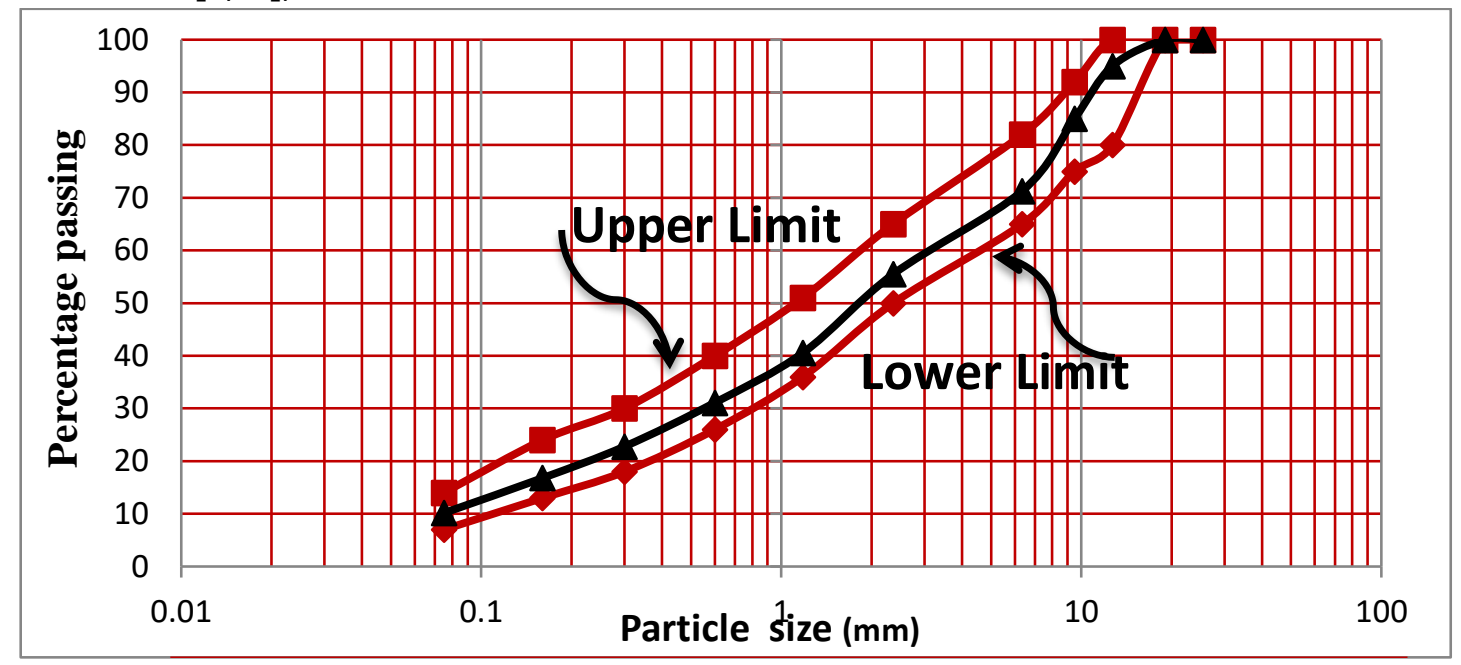

Figure 8: Gradation of final aggregate mix with ASTM specification range

Table 2: Tests on aggregates

\begin{tabular}{llllll}
\hline S/N & Tests & Results & Unit & $\begin{array}{l}\text { Specification } \\
(\text { NGSRB } 2016)\end{array}$ & Comment \\
\hline 1. & Impact value & 20.45 & $\%$ & $<30$ & Satisfactory \\
2. & Crushing value & 20.25 & $\%$ & $<30$ & Satisfactory \\
3. & Aberration value & 24.00 & $\%$ & $<30$ & Satisfactory \\
4. & Elongation index & 20.18 & $\%$ & $<35$ & Satisfactory \\
5. & Flakiness index & 12.87 & $\%$ & $<30$ & Satisfactory \\
6. & $\begin{array}{l}\text { Specific Gravity of } \\
\text { coarse aggregates }\end{array}$ & 2.6 & NIL & $2.5-2.9$ & Satisfactory \\
7. & $\begin{array}{l}\text { Specific Gravity } \\
\text { fine aggregates }\end{array}$ & 2.58 & NIL & $2.5-2.9$ & Satisfactory \\
\hline
\end{tabular}

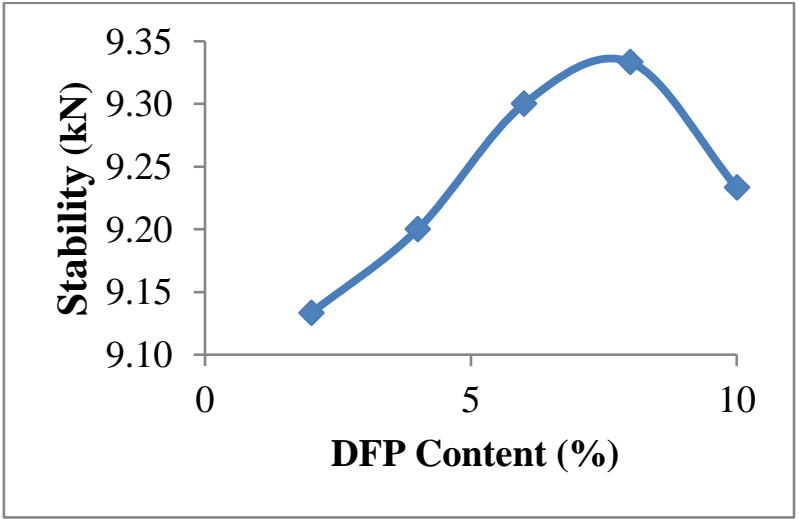

Figure 9: Variation of Stability with DFP Content

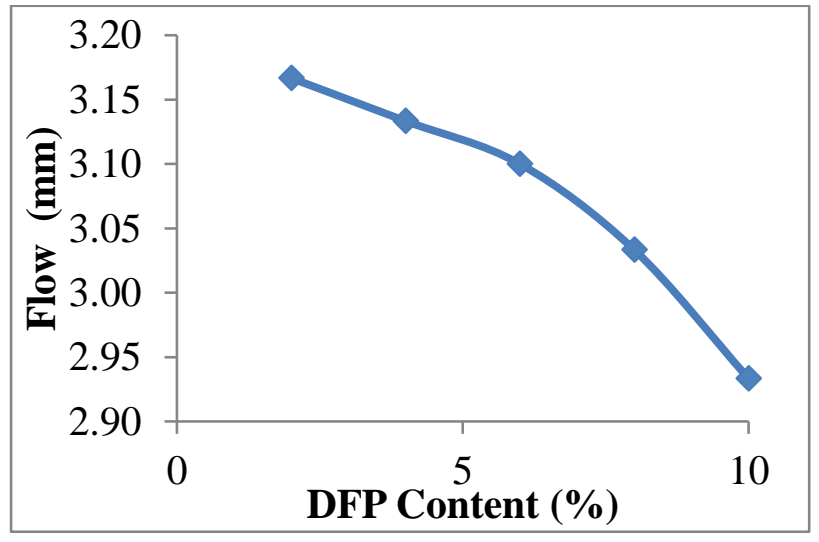

Figure 10: Variation of flow with DFP content 


\subsubsection{VIM - DFP content relationship}

The results of the variation of air void with DFP are presented in Figure 13. It can be revealed that air voids decreased to $4.7 \%$ at $6 \%$ DFP, with increased concentration of DFP in the mixes. The amount of air voids present in the mix is a very important design criterion. This follows a similar trend to the work of [9].

\subsubsection{VFB - DFP content relationship}

Variation of VFB with DFP content is presented in Figure 14. It was observed that the VFB increased as modifier content is increased until it reaches maximum value of $75 \%$ at $6 \%$ DFP before it decreased. This is as a result of the modifier filling up more voids in the hot-mix asphalt thereby decreasing the VFB. A study justified by both the work of $[25,9]$ as VFP decreased to $53.81 \%$ at $2.5 \%$ before increasing.

\subsection{Determination of Optimum Modifier (DFP) Content}

The optimum DFP content was then determined to be $6.7 \%$ of the total mass of the HMA. This was obtained by determining the DFP content at the highest stability, highest value of bulk density, and median of allowed percentages of air voids. The optimum DFP content was then used to determine the optimum value of the stability, flow, unit weight VMA, VIM and VFB which were all in agreement with the specifications prescribed by [24] for a wearing course as shown in Table 3.

The optimum DFP content was also used to determine the optimum value of all consistency tests carried out on bitumen which were all in agreement with the specifications prescribed by [24] as shown in Table 4. The results presented in Table 3 and 4 showed that all properties of modified bitumen and modified HMA at $6.7 \%$ DFP Contents meet the specification of [24]. This indicates that the strength of the material is improved hence, the life span and durability of asphalt mixtures is also improved.

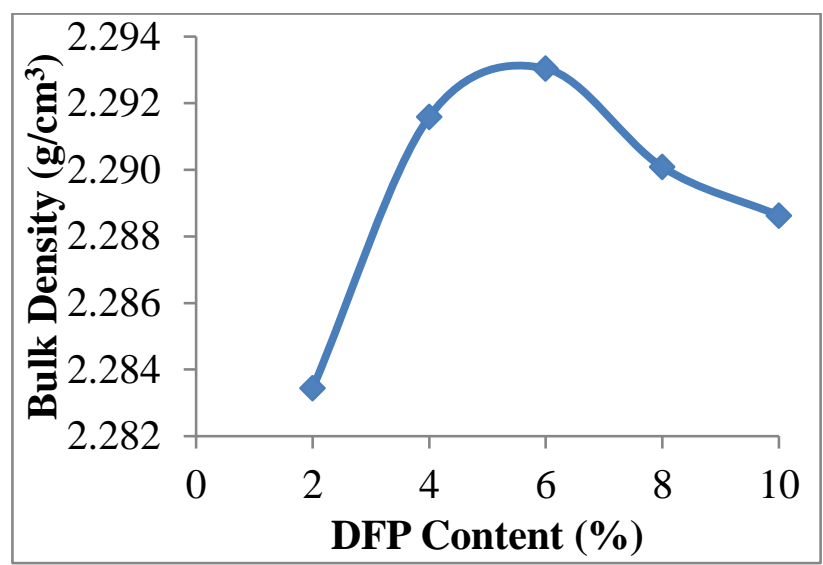

Figure 11: Variation of Bulk density with DFP content

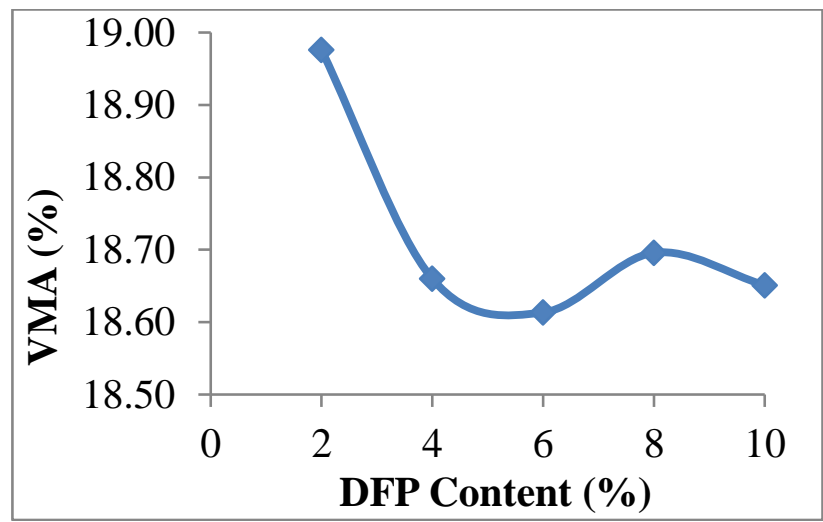

Figure 12: Variation of VMA with DFP content

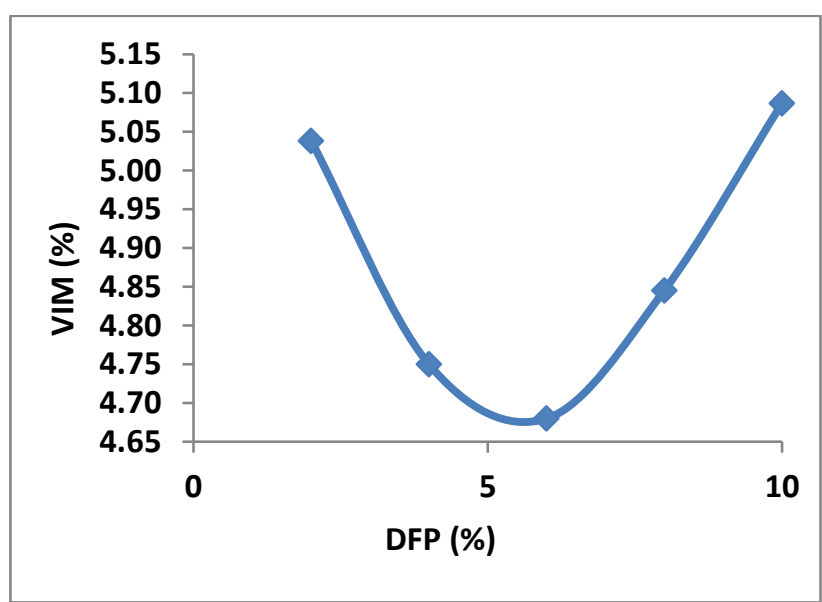

Figure 13: Variation of VIM with DFP content

Table 3: Properties of HMA at 6.7\% DFP Content [24]

\begin{tabular}{|c|c|c|c|}
\hline Test & 6.7\% DFP Content & Min. Specs. & Max. Specs. \\
\hline Stability $(\mathrm{kN})$ & 9.34 & 3.5 & ------------- \\
\hline Flow (mm) & 3.05 & 2.0 & 4.0 \\
\hline Bulk Density $\left(\mathrm{g} / \mathrm{cm}^{3}\right)$ & 2.292 & ---------------- & --------------- \\
\hline VMA \% & 18.55 & ------------ & ------ \\
\hline VIM \% & 4.7 & 3.0 & 5.0 \\
\hline VFB \% & 75 & 75 & 82 \\
\hline
\end{tabular}


Table 4: properties of bitumen at 6.7\% DFP Content [24]

\begin{tabular}{lllll}
\hline S/N & Test Conducted & Unit & Result & Specification \\
\hline 1 & Penetration & $0.1 \mathrm{~mm}$ & 63 & $60-70$ \\
2 & Softening point & ${ }^{\circ} \mathrm{C}$ & 53 & $48-56$ \\
3 & Ductility @ $25^{\circ} \mathrm{C}$ & $\mathrm{cm}$ & 103 & 100 (Minimum) \\
4 & Specific gravity & NIL & 1.015 & $1.01-1.06$ \\
\hline
\end{tabular}

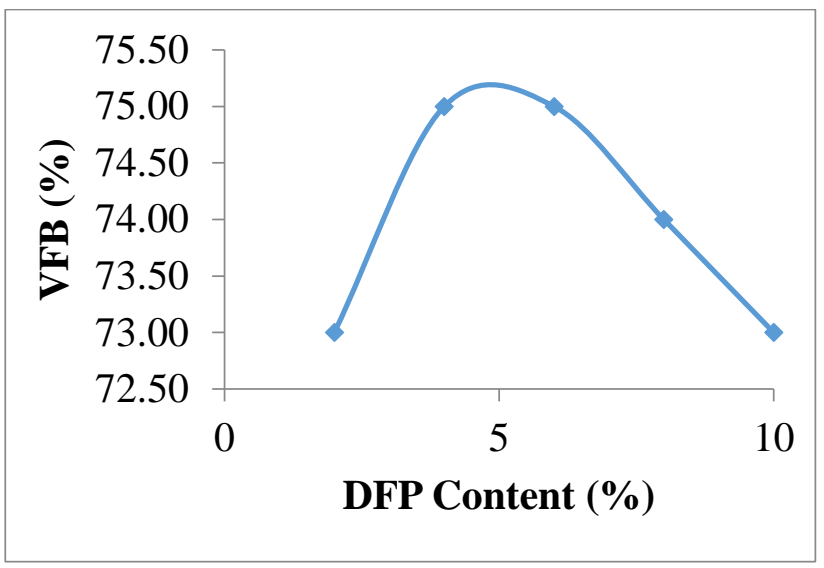

Figure 14: Variation of VFB with DFP content

\section{ECONOMIC AND ENVIRONMENTAL IMPLICATIONS}

Based on the results from this study and the fact that $92.3 \%$ of paved roads globally are flexible pavements [26], DFP could be considered for modification of bitumen. Utilization of these wastes in flexible pavement construction and road rehabilitations would significantly mop up several million metric tons of the DFP from the waste stream which would have positive effects on the environment such as reduction of environmental pollution and burdens from littered plastics, elongated service lives of landfills, and conservation of natural resources used in production of asphalt. It also enhances ecosystem balance by the removal of non-biodegradable DFP from the ecosystem [27]. Likewise, utilization of the DFPmodified bitumen in flexible pavements would significantly improve the service lives of our roads with economic implications such as provision of extra source of income for waste managers, reduction of construction and maintenance costs of flexible pavements, reduction of accidents, and facilitation of smooth and enjoyable rides for commuters [11].

\section{CONCLUSIONS AND RECOMMENDATIONS}

\subsection{Conclusions}

1. The Modified Bitumen shows an increase in softening point but a decrease in ductility, specific gravity and penetration as modifier content is increased. This is an indication of increase in rutting resistance and decrease in temperature susceptibility.

2. The optimum DFP content by weight of $\mathrm{OBC}$ is found to be $6.7 \%$.

\subsection{Recommendations}

1. From this study, Disposable Food Pack modified bitumen is recommended for road construction because of the relative compatibility and enhancement it provides to conventional bitumen.

2. Based on the marshal test conducted, an optimum modifier content of $6.7 \%$ by weight of the $\mathrm{OBC}$ is recommended for use in the hot-mix asphaltic wearing course.

3. Further research continues to investigate the rheological properties of Mix with DFP-Modifiedbitumen.

\section{REFERENCES}

[1] A. Sojobi and H. Owamah, "Evaluation of the Suitability of Low-Density Polyethylene (LDPE) Waste as Fine Aggregates in Concrete," Nigerian Journal of Technology, vol. 33, no. 4, pp. 409425, 2014.

[2] V. S. Punith and A. Veeraragavan, "Evaluation of reclaimed polyethylene-modified asphalt pavements," Journal of Testing and Evaluation, vol. 38, no. 5, pp. 541-548, 2010.

[3] N. Habib, I. Kamaruddin, M. Napiah and I. M. Tan, "Effect of Mixing Process on Polypropylene Modified Bituminous Concrete Mix Properties," World Academy of Science Engineering and Technology, vol. 5, no. 10, pp. 477-482, 2011.

[4] A. Gawande, G. Zamare, V. C. Renge, S. Tayde and G. Bharsakaleb, "An overview on waste plastic utilization in asphalting of roads.," Journal of Engineering Research and Studies, vol. 3, no. 2, pp. 33-40, 2012.

[5] I. Aliyu, A. Usman, J. Kaura, M. Ashiru and I. Kingsley, "Polyethylene from Water Sachet as a 
Modifier in Hot Asphalt Mixture," Department of Civil Engineering, Ahmadu Bello University, Zaria, Nigeria, 2015.

[6] Z. N. Kalantar, A. Mahrez and M. R. Karim, "Properties of Bituminous Binder Modified With Waste Polyethylene Terephthalate," in Malaysian Universities Transportation Research Forum and Conferences, Malaysia, 2010.

[7] R. Vasudevan, C. S. A. Ramalinga, B. Sundarakannan and R. Velkennedy, "A technique to Dispose Waste Plastics in an Ecofriendly way - Application in Construction of Flexible Pavements," Construction and Building Materials, vol. 28, no. 1, pp. 311-320, 2012.

[8] S. Taih, "The Effect of Additives in Hot Asphalt Mixtures," Journal of Engineering and Development, vol. 15, no. 3, pp. 131-150, 2011.

[9] A. Mohammad, "Use of Waste Plastic Blended Bitumen for Road Construction and Maintenance," Master of Engineering thesis, Bangladesh University of Engineering and Technology, Bangladesh, 2012.

[10] M. D. Rahman, U. Ahmed, M. Sobhan and T. U. Ahmed, "Performance Evaluation of Waste Polyethylene and PVC on Hot Asphalt Mixtures," American Journal Of Civil Engineering And Architecture, vol. 1, no. 5, pp. 97-102, 2013.

[11] A. O. Sojobi, S. E. Nwobodo and O. J. Aladegboye, "Recycling of Polyethylene Terephthalate (PET) Plastic Bottle Wastes in Bituminous Asphaltic Concrete," Civil and Environmental Engineering Research Article, Cogent Engineering, vol. 3, pp. 1-28, 2016.

[12] ASTM D5 / D5M-20, Standard Test Method for Penetration of Bituminous Materials, West Conshohocken, PA: ASTM international, 2020.

[13] ASTM D36 / D36M-14, Standard Test Method for Softening Point of Bitumen (Ring-and-Ball Apparatus), vol. 04.04, West Conshohocken, PA: ASTM international, 2020.

[14] ASTM D113-17, Standard Test Method for Ductility of Asphalt Materials, vol. 04.03, West Conshohocken, Philadelphia.PA: ASTM International, 2017.

[15] ASTM D4402, Standard test method for viscosity determination of asphalt at elevated temperatures using a rotational viscometer, West Conshohocken, Philadelphia, PA: ASTM International, 2015.

[16] ASTM D2170 / D2170M-18, Standard Test Method for Kinematic Viscosity of Asphalts, vol.
04.03, West Conshohocken, PA: ASTM International, 2018.

[17] ASTM D92-18, Standard Test Method for Flash and Fire points by Cleveland Open Cup Tester, vol. 05.01, West Conshohocken, PA: ASTM International, 2018.

[18] ASTM D2042-15, Standard Test Method for Solubility of Asphalt Materials in Trichloroethylene, West Conshohocken, PA: ASTM International, 2015.

[19] ASTM C136 /C136M-19, Standard Test Method for Sieve Analysis of Fine and Coarse Aggregates, West Conshohocken, PA: ASTM International, 2019.

[20] ASTM C131 / C131M-20, Standard Test Method for Resistance to Degradation of Small-Size Coarse Aggregate by Abrasion and Impact in the Los Angeles Machine, West Conshohocken, PA: ASTM International, 2020.

[21] ASTM D4791-19, Standard Test Method for Flat Particles, Elongated Particles, or Flat and Elongated Particles in Coarse Aggregate, West Conshohocken, PA: ASTM International, 2019.

[22] ASTM C127-15, Standard Test Method for Relative Density (Specific Gravity) and Absorption of Coarse Aggregate, West Conshohocken, PA: ASTM International, 2015.

[23] ASTM D6926-16, Standard Practice for Preparation of Asphalt Mixture Specimens Using Marshall Apparatus, West Conshohocken, Philadelphia, PA: American Society for Testing and Materials (ASTM) International, 2016.

[24] FMWH, Nigerian General Specification for Roads and Bridges, vol. II, Lagos, Nigeria: Federal Ministry of Works and Housing (FMWH), 2016, p. 183.

[25] H. Z. Noor, I. Kamaruddin, M. Napiah and I. M. Tan, "Rheological Properties of Polyethylene and Polypropylene Modified Bitumen," International Journal of Civil and Environmental Engineering, vol. 4, no. 12, pp. 381-385, 2012.

[26] K. Blazejowski, Stone Matrix Asphalt: Theory and Practice., LLC, New York, NY: CRC Press Taylor and Francis Group, 2011.

[27] E. Ahmadinia, M. Zargar, M. Karim, M. Abdelaziz and P. Shafigh, "Using Waste Plastic Bottles as Additive for Stone Mastic Asphalt," Materials \& Design, vol. 32, pp. 4844-4849, 2011. 